\title{
Mapa estratégico, uma representação gráfica do Balanced Scorecard, ferramenta para otimização da tomada de decisões: estudo de caso de uma indústria de porte médio
}

\author{
Clane Regina Rech Storch (UNISC) clane@viavale.com.br \\ Elpídio Oscar Benitez Nara (UNISC) elpidio@unisc.br \\ Luiz Afonso Storch (UNISC) luizafonso@viavale.com.br
}

\begin{abstract}
Resumo
Atualmente as empresas preocupadas em melhorar sua capacidade de competitividade frente ao ambiente globalizado existente buscam novas ferramentas de gestão, para tanto o presente trabalho objetiva propor um mapa estratégico, baseado na metodologia do Balanced Scorecard, para uma indústria de porte médio do ramo de plásticos. São descritos os principais conceitos relacionados com o assunto, enfatizando, planejamento estratégico e Balanced Scorecard. Nessa nova forma de gerenciamento, destaca-se como instrumento da maior importância, a construção do mapa estratégico elaborado a partir da missão, visão, estratégias, objetivos e perspectivas levantadas na organização, que possuam abrangência e coerência compativeis com a atualidade e que permitam, sobretudo, considerar a importância crescente dos valores intangíveis frente aos tradicionais valores físicos.

Palavras chave: Planejamento estratégico, Balanced Scorecard, Mapa estratégico.
\end{abstract}

\section{Introdução}

Constantes transformações ocorrem no ambiente que circunda as empresas ocasionando grandes processos de mudanças nas organizações, visando melhorar as condições de competitividade, lucratividade e qualidade dos produtos e serviços, as organizações necessitam de alternativas que viabilizem a avaliação de seu desempenho, sendo que a estratégia da empresa deve ser traduzida em resultados, que passam a ser acompanhados através de um sistema de gestão bem estruturado.

O processo de gestão empresarial passa por novos desafios e os gestores passam a trabalhar com novos modelos de decisão. Um grande volume de métodos, técnicas, abordagens e preocupações desafiam a capacidade dos gestores no que diz respeito ao entendimento dessas questões, ao discernimento do que é ou não relevante, e principalmente, a como implementar as mudanças e obter resultados concretos, (CATELLI, 1999).

Radünz (2002) cita que as organizações estão voltadas para a valorização de ativos intangíveis, que permitem que a empresa esteja ligada diretamente ao cliente, traduzindo as necessidades, segmentando novos mercados e clientes, preocupando-se com serviços pré e pós-venda, inovando, minimizando custos e aumentando a qualidade do produto, ou seja, estão voltadas aos fatores operacionais ligados e adaptados ao novo ambiente. Por isso precisa-se de um sistema de gestão integrado, que reúna todas as informações para que a empresa realmente alcance os resultados planejados, sendo a ferramenta mais indicada para isso o Balanced Scorecard.

\section{Objetivo geral}

Desenvolver um mapa estratégico, ou seja, uma representação gráfica do Balanced Scorecard, para otimização da tomada de decisões para uma indústria de porte médio. 


\subsection{Objetivos específicos}

Identificar e ressaltar a importância da formulação das estratégias.

Pesquisar e levantar as perspectivas existentes em relação ao Balanced Scorecard na empresa.

Desenvolver um mapa estratégico baseado nas estratégias e perspectivas.

\section{Metodologia}

Quanto a sua natureza, o estudo desenvolvido segue a abordagem de uma Pesquisa Aplicada, que, conforme Silva e Menezes (2000, p. 20), "objetiva gerar conhecimentos para aplicação prática dirigidos à solução de problemas específicos". Considerando-se os objetivos estabelecidos no estudo, esta se caracteriza como uma pesquisa exploratória. Segundo Gil (1991), esta assume, em geral, as formas de Pesquisas Bibliográficas e Estudos de Caso. Esta linha de opção se deu em função da forma de Estudo de Caso que foi adotada para propor um mapa estratégico baseado no Balanced Scorecard.

\section{Planejamento estratégico}

Muitos sistemas de planejamento estratégico concentram-se particularmente em detalhes operacionais e financeiros e não no posicionamento competitivo, levando muitas empresas a perderem de vista as questões críticas de competitividade que deveriam ser abordadas pelo planejamento. Mintzberg (apud CORAL, 2002, p. 50) define planejamento estratégico da seguinte forma:

\footnotetext{
"Processo pelo qual a estratégia da organização é formulada essencialmente num dado momento de um processo detalhado, onde todas as grandes decisões vão ser interrelacionadas. Por isso, o planejamento força a organizar suas estratégias globais e a desenvolver um senso explícito de direção estratégica. O planejamento é orientado para análise sistemática e detalhada e visa compreender o ambiente para poder influenciá-lo".
}

Graeml (2000), cita que o planejamento estratégico e a análise de risco não são precisos nem dão garantias de sucesso. Seu objetivo é aumentar a probabilidade de ocorrência de fatos favoráveis, maximizando o retorno de investimento e minimizando a gravidade e as chances de ocorrência de fatos desfavoráveis.

O Planejamento Estratégico, na verdade, nada mais é do que uma saída, além de uma necessidade para as empresas que desejam realizar uma gestão controlada de seus negócios e que tenham uma visão pró-ativa. Entretanto, não está restrito apenas as grandes corporações, mas sim, presente nos mais variados níveis sociais. Independente de termos essa definição e conhecimento, Mintzberg e Quinn (2001, p. 14), afirmam que "a imagem do planejamento há muito tempo popular na literatura, distorce esses processos e, desta forma, desorienta as organizações que a abraçam de forma descomprometida". Nesta mesma linha de atuação, Aaker (2001, p. 16), define que "a abrangência de um negócio é definida pelos produtos que ele oferece e decide não oferecer, pelos mercados que busca servir e não servir, pelos competidores que escolhe para competir e evitar e pelo nível de integração vertical do próprio negócio".

De acordo com Oliveira (1995, p. 43), “o planejamento estratégico relaciona-se com objetivos de longo prazo e com maneiras e ações para alcançá-los que afetam a empresa como um todo". Segundo Bennet et al (2001), o que distingue as empresas bem sucedidas é a forma como se organizam e operam para concretizar suas aspirações, ou seja, a chave para melhorar o desempenho está em implementar a estratégia. Mintzberg e Quinn (2001, p. 20) citam que a "estratégia é o padrão ou plano que integra as principais metas, políticas e seqüencias de ações de uma organização em um todo coerente". 
“O Planejamento Estratégico não é um instrumento isolado, pois, possui suas bases em análises internas (da empresa) e análises do ambiente, o que permite um desenvolvimento de ações voltadas para o mercado, baseadas em vantagens competitivas que garantirão o sucesso organizacional". (PORTO, ESTRADA e BOECK, 2004, p. 3)

Conforme Kato (2000, p. 37), "para se avaliar a implantação da Estratégia Competitiva de uma empresa, é necessário a utilização de um instrumento gerencial evidenciar o sucesso ou fracasso das decisões tomadas".

\section{Balanced Scorecard (BSC)}

Na opinião de Martins (1998), a empresa deve criar riqueza e isso requer que as informações possibilitem aos executivos fazer julgamentos informados, tanto acerca de diagnósticos da situação quanto à respeito de questionar a estratégia e as suposições da empresa sobre o negócio dela. O sistema de informação de gestão torna possíveis diagnósticos, estratégias e decisões e também destaca a necessidade da informação preditiva para focalizar os fatores que irão conduzir ao desempenho futuro desejado e, dessa forma, será possível atingir a melhoria com êxito maior.

O modelo de avaliação de desempenho Balanced Scorecard desenvolvido por Kaplan e Norton (1997), teve como objetivo desenvolver um novo modelo de medição de desempenho para as organizações que refletisse o equilíbrio entre objetivos de curto e longo prazo, entre medidas financeiras e não financeiras e, também, medisse o desempenho sob as perspectivas: financeira, do cliente, dos processos internos e do aprendizado e crescimento. Para Neely et al., citado por Bond e Carpinetti (1999) a medição de desempenho pode ser compreendida como a técnica usada para quantificar a eficiência e a eficácia das atividades de negócio.

Considerando as mudanças ocorridas, ao longo dos anos anteriores, nos métodos existentes de avaliação do desempenho empresarial, que se baseavam apenas em indicadores contábeis e financeiros, e que, gradativamente, vinham se tornando insuficientes, Rocha (2002), nos coloca que o BSC surge com a utilidade de manter sempre o dia-a-dia dos gerentes conectados diretamente à estratégia empresarial. Esta conexão se dará através da visualização dos indicadores de desempenho sobre o comportamento de cada área e de cada ponto relevante escolhido pela organização. O BSC é um sistema de gestão, baseado em indicadores que impulsionam o desempenho, proporcionando à organização visão do negócio atual e futura, de forma abrangente. Como Stewart (1998, p. 46) expôs, "as empresas estão no negócio para ganhar dinheiro e seu sucesso ou fracasso final são expressos em termos financeiros, mas a linguagem da gerência é, cada vez mais, não financeira”.

O Balanced Scorecard deve traduzir a missão e a estratégia da organização em objetivos e medidas tangíveis. As medidas representam o equilíbrio entre indicadores externos voltados para acionistas e clientes, e as medidas internas dos processos críticos de negócios, inovação, aprendizado e crescimento (KAPLAN e NORTON, 1997). As empresas criativas usam o BSC como um sistema de gestão estratégica uma vez que o método introduz uma nova forma de abordar e chamar a atenção dos gerentes para os quatro aspectos mais importantes que, separada ou complementarmente, contribuem para conectar os objetivos estratégicos a longo prazo aos resultados e ações a curto prazo, segundo Campos (1998).

"O BSC surge com o objetivo de resolver os problemas que existem em se ter uma única visão, ou perspectiva como preferem os autores, na condução das tomadas de decisão em uma organização, contrapondo a contabilidade tradicional, que usa uma linha exclusivamente financeira". (ROCHA, 2002, p. 48) 


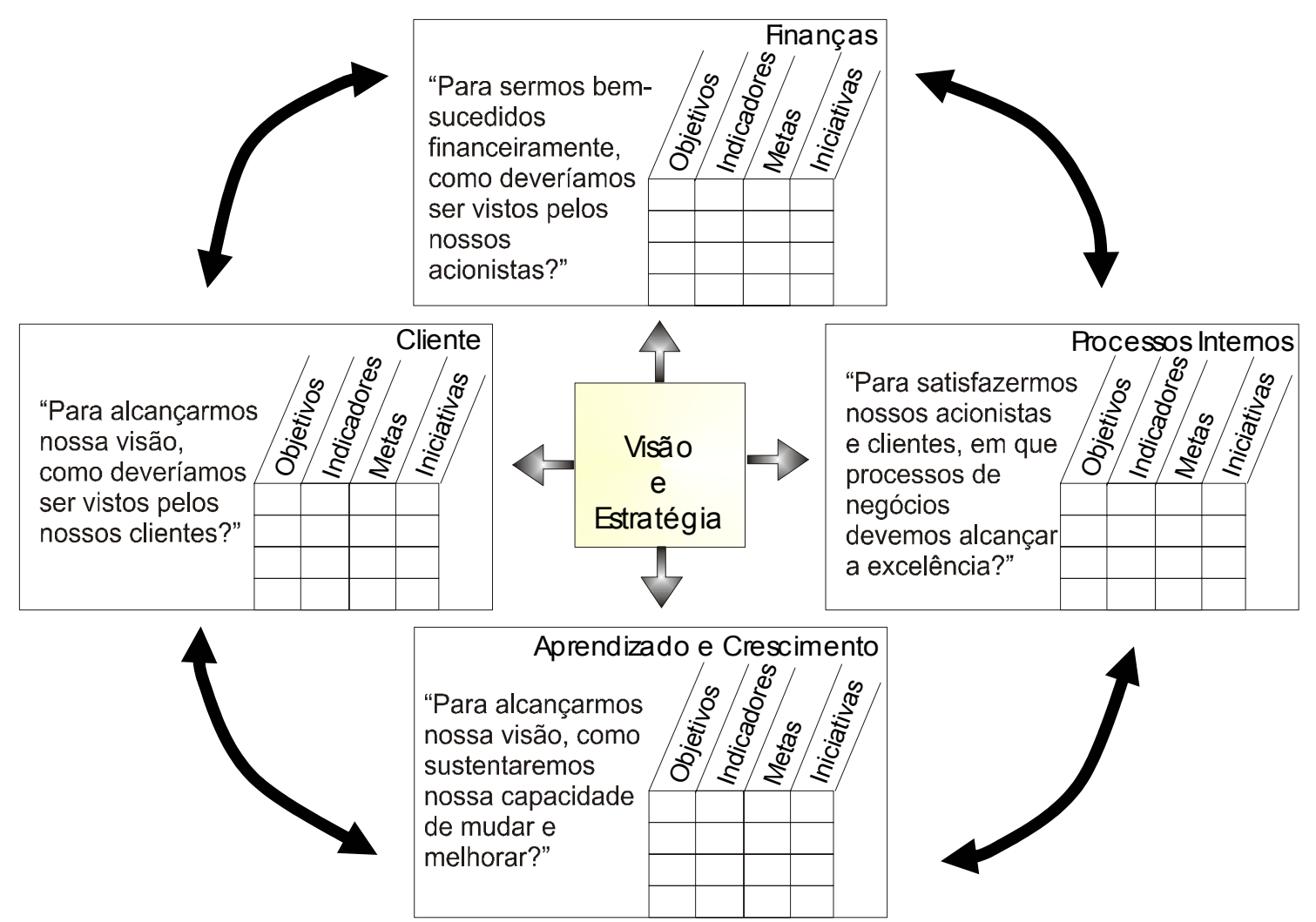

Figura 1 - O BSC fornece a estrutura necessária para a tradução da estratégia em termos operacionais.

Fone: Kaplan e Norton, 1997, p. 10.

Segundo Soares Jr. e Prochnik (2004, p. 11), é importante que os indicadores sejam claramente definidos e que as responsabilidades de sua implantação sejam bem delineadas, evitando-se trocar indicadores em curto espaço de tempo, sem se ter confirmação mais perene de sua adequação. "Mesmo nas organizações que já tinham o costume de trabalhar com indicadores, o BSC reforça a necessidade de se perseguir um conjunto de indicadores com novas propriedades, isto é, que revele um equilíbrio entre o curto e o longo prazo, entre medidas de ocorrência e de tendência e entre diferentes perspectivas, não destacando somente a perspectiva financeira".

Cada uma das perspectivas do Balanced Scorecard busca um referencial relevante para uma forma de implementar o desenvolvimento da estratégia na organização em questão. Este caminho escolhido para implementar o BSC é amparado pela visão sistêmica, a qual indica que tudo está interligado em uma teia de relações, conectando a empresa ao meio-ambiente no qual está inserida. As quatro perspectivas que compõem o BSC e que alavancam o desempenho futuro são: financeira, do cliente, dos processos internos e de aprendizado e crescimento, conforme demonstrado na figura 1.

\subsection{O BSC e a gestão do conhecimento}

Segundo Hernandes, Cruz e Falcão (2000, p. 3), "gestão do conhecimento é o processo pelo qual uma organização consciente e sistematicamente coleta, cria, organiza, compartilha e quantifica seu acervo de conhecimentos para atingir seus objetivos estratégicos". Essas atividades são dependentes da junção de políticas de gestão de recursos humanos, estruturas e culturas organizacionais e tecnologias adequadas. Como o conhecimento é orientado à ação, a gestão do conhecimento deve promover a execução de ações alinhadas com os objetivos estratégicos da organização. 
Na opinião de Paul Arveson (apud Hernandes, Cruz e Falcão, 2000, p.2), deve-se contratar as pessoas certas, treina-las, motivá-las e orientá-las corretamente, bem como tornar o processo de aprendizado contínuo. A cultura organizacional voltada para o aprendizado e crescimento encoraja as pessoas a fazer sugestões e questionar o status quo, gerando um fluxo contínuo de sugestões e idéias que permitirão o melhoramento dos processos internos. Estes, por sua vez, levam ao aprimoramento dos produtos e serviços e possibilitam a elevação da satisfação dos clientes. A melhoria na satisfação dos clientes os torna leais e aumenta a fatia de mercado da empresa, o que afeta diretamente os resultados financeiros, como lucro, receita e retorno sobre o investimento.

\section{Proposta de implantação de um BSC para uma indústria de porte médio}

O principal objetivo é a identificação de indicadores que melhor comuniquem o significado da estratégia. Para Kaplan e Norton (1997, p. 320) “como cada estratégia é única, cada scorecard deve ser único e conter vários indicadores únicos".

Inicialmente, percorreu-se alguns passos para o levantamento das informações necessárias para se propor a implantação de um mapa estratégico baseado no Balanced Scorecard para a empresa pesquisada, tais como:

- Conhecer e trabalhar a missão, visão e as estratégias da empresa;

- Definição das perspectivas e agrupamento dos objetivos, em relação às mesmas. Pela análise dos objetivos estratégicos, verifica-se que as quatro perspectivas enunciadas por Kaplan e Norton (1997) não são suficientes para abranger toda a estratégia formulada pela empresa. A empresa optou por inserir outra perspectiva em seu mapa estratégico, Responsabilidade Social, que já faz parte do dia-a-dia da empresa. O Instituto Ethos (apud Masini, 2004), uma das associações que valoriza e ensina, literalmente, o caminho das pedras em relação ao assunto em pauta traz uma definição simples:

\footnotetext{
"Responsabilidade Social é uma forma de conduzir os negócios da empresa de tal maneira que a torna parceira e co-responsável pelo desenvolvimento social. A empresa socialmente responsável é aquela que possui a capacidade de ouvir os interesses das diferentes partes (acionistas, funcionários, prestadores de serviço, fornecedores, consumidores, comunidade, governo e meio-ambiente) e conseguir incorporá-los no planejamento de suas atividades, buscando atender às demandas de todos e não apenas dos acionistas ou proprietários".
}

Conforme Vilhena (2004), no atual ambiente de mercado - cada vez mais competitivo - as ações de responsabilidade social podem representar fontes de vantagens competitivas para as empresas. "O compromisso com o social ultrapassa a necessidade de compreender definições e conceitos sobre responsabilidade social corporativa. Antes, porém, a responsabilidade social é um valor e uma postura que se refletem nas decisões, atitudes e ações das empresas, empresários, funcionários e parceiros", segundo Mueller (2003).

- Classificação dos indicadores estratégicos conforme as perspectivas, estratégias e objetivos da empresa. Segundo Hikage, Carvalho e Laurindo (2003, p.3), "os indicadores permitem acompanhar o andamento de um processo identificando riscos em potencial e problemas antes de se tornarem críticos além de controlar a qualidade de um processo bem como a produtividade e auxílio na tomada de decisões". Permite que a organização obtenha informações relevantes para a eficiência do processo, no entanto deve-se tomar cuidado quando se tratar de medições estratégicas, uma vez que uma escolha inadequada poderá levar a resultados errôneos.

Os indicadores de desempenho foram levantados dando-se preferência para aqueles que o sistema de informação existente suportasse, facilitando uma possível implantação. $\mathrm{O}$ 
estabelecimento dos objetivos e indicadores dependeram diretamente das estratégias estabelecidas pela empresa.

- E por último, a proposta do mapa estratégico, segundo as informações levantadas na empresa.

\subsection{Proposta do Mapa estratégico}

Segundo Kaplan e Norton (2000), o mapa estratégico do Balanced Scorecard explicita a hipótese da estratégia, e cada indicador se converte em parte integrante de uma cadeia lógica de causa e efeito que conecta os resultados almejados da estratégia. $\mathrm{O}$ mapa estratégico descreve o processo de transformação de ativos intangíveis em resultados tangíveis para os clientes e, por conseguinte, em resultados financeiros. Essa ferramenta fornece aos executivos um referencial para a descrição e gerenciamento da estratégia.

Desta forma verifica-se no mapa estratégico (ver anexo 1) que a responsabilidade social dentro e fora da organização contribui para o alcance dos objetivos em todas as demais perspectivas do BSC, a promoção do desenvolvimento profissional, através da elaboração de um plano de cargos e salários e realização de cursos e treinamentos, pode contribuir para ter uma mão-de-obra melhor qualificada, que poderia auxiliar na produção de bens e serviços com qualidade superior, maior valor agregado e inovações, que por sua vez, contribuiriam para elevar o grau de satisfação dos clientes no que diz respeito à qualidade dos produtos e serviços fornecidos, sendo que clientes satisfeitos, normalmente, elevam as vendas, conseqüentemente, aumentando o retorno sobre o investimento.

\section{Considerações finais}

O trabalho propôs um mapa estratégico utilizando o Balanced Scorecard, para alcançar a melhoria na qualidade dos produtos/serviços e vantagens competitivas, pois com o rápido desenvolvimento das organizações, dos mercados e principalmente da concorrência, este sistema constitui-se em um importante diferencial para se antecipar aos concorrentes, oferecendo maior qualidade de serviços aos clientes e melhorando os aspectos internos e externos da organização.

Enfim, o trabalho visa contribuir para a aplicação de um sistema de gestão estratégica, a ser implantada em organizações que queiram adotar um gerenciamento integrado às estratégias da organização, com o foco no mercado, nos ativos tangíveis e intangíveis, e com flexibilidade para mudar suas estratégias à medida que sinta as alterações nos seus indicadores.

\section{Referências}

AAKER, David A. (2001) - Administração estratégica de mercado. Tradução: Martin Albert Haag e Paulo Ricardo Meira. $5^{\text {a }}$ ed. Porto Alegre: Editora Bookman.

BENNETT, J. W. et al. (2001) - Um novo modelo para implementar a estratégia. Revista HSM Management. Maio/Junho, p. 16-22.

BOND, Emerson; CARPINETTI, Luiz. (1999) - Medição de Desempenho. Disponível em http://www.numa.org.br. Acessado em 26/10/2002.

CAMPOS, J. A. (1998) - Cenário balanceado: painel de indicadores para a gestão estratégica dos negócios. São Paulo: Aquariana.

CATELLI, Armando. (1999) - Controladoria: uma abordagem da gestão econômica. São Paulo: Atlas.

CORAL, Eliza. (2002) - Modelo de Planejamento Estratégico para a Sustentabilidade Empresarial. Tese de Doutorado (Programa de Pós-Graduação em Engenharia de Produção). Florianópolis: UFSC.

GIL, Antônio Carlos. (1991) Como elaborar projetos de pesquisa. 3. ed. São Paulo: Atlas. 
GRAEML, Felipe Reis. (2000) - Indicadores Estratégicos: uma ferramenta de auxílio na Administração Municipal. Dissertação de Mestrado (Programa de Pós-Graduação em Engenharia de Produção). Florianópolis: UFSC.

HERNANDES, C. A. M.; CRUZ, C. S.; FALCÃO, S. D. (2000) - Combinando o Balanced Scorecard com a gestão do conhecimento. Caderno de Pesquisas em Administração. $2^{\circ}$ trim. São Paulo.

HIKAGE, Oswaldo Keiji; CARVALHO, Marly Monteiro de; LAURINDO, Fernando José Barbin. (2003) Praticando o processo de implementação de estratégia utilizando o Balanced Scorecard. Anais do XXIII Encontro Nac. de Eng. de Produção - Ouro Preto/ MG, Outubro de 2003.

KAPLAN, R. S.; NORTON, D. P. (1997) - A estratégia em ação: Balanced Scorecard. Rio de Janeiro: Campus. (2000) - Organização orientada para a estratégia: como as empresas que adotam o Balanced Scorecard prosperam no novo ambiente de negócios. Rio de Janeiro: Campus.

KATO, J. M. (2000) - Estratégia competitiva e avaliação de desempenho aplicados a uma empresa de previdência privada aberta no Brasil. Dissertação de Mestrado (Programa de Pós-Graduação em Engenharia de Produção). Florianópolis: UFSC.

MASINI, Marcos. (2004) - Responsabilidade Social: e o público interno, como é que fica? Disponível em: http://www.universiabrasil.net/materia_voluntariado.jsp?id=4013. Acessado em 13/05/2004.

MARTINS, Roberto A. (1998) - Sistemas de Medição de Desempenho: um modelo para estruturação do uso. Tese de Doutorado. São Paulo: Escola Politécnica da USP.

MINTZBERG, H.; QUINN, J. B. (2001) - O processo da estratégia. 3ª Edição. Porto Alegre: Bookmann.

MUELLER, Adriana. (2003) - A utilização dos indicadores de responsabilidade social corporativa e sua relação com os stakeholders. Dissertação de Mestrado (Programa de Pós-Graduação em Engenharia de Produção). Florianópolis: UFSC.

OLIVEIRA, D. P. R. (1995) - Planejamento estratégico: conceitos, metodologia e práticas. 9a Edição. São Paulo: Atlas.

PORTO, Adriana; ESTRADA, Rolando Juan Soliz; BOECK, Elida Cristina. (2004) - Indicadores de Desempenho e o seu Alinhamento com o Planejamento Estratégico: Um estudo de caso na média indústria do setor moveleiro. Anais do XVII Congresso da Slade - Sociedade Latino-Americana de Estratégia. ItapemaCamboriu/SC, Abril de 2004.

RADÜNZ, R. G. (2002) - Sistema de informação para a avaliação de desempenho de atacados baseado na metodologia Balanced Scorecard. Dissertação de Mestrado (Programa de Pós-Graduação em Engenharia de Produção). Florianópolis: UFSC.

ROCHA, Augusto César Barreto. (2002) - Configuração de um sistema de avaliação de desempenho alicerçado no Balanced Scorecard para uma indústria de confecções de porte médio. Dissertação de Mestrado (Programa de Pós-Graduação em Engenharia de Produção). Florianópolis: UFSC.

SILVA, Edna Lúcia da; MENEZES, Estera Muszkat. (2000) - Metodologia da Pesquisa e Elaboração de Dissertação. Florianópolis: Laboratório de Ensino a Distância da UFSC.

SOARES Jr., Heles; PROCHNIK, Victor. (2004) - Experiências comparadas de implantação do Balanced Scorecard no Brasil. Anais do XVII Congresso da Slade - Sociedade Latino-Americana de Estratégia. ItapemaCamboriu/SC, Abril de 2004.

STEWART, T. A. (1998) - Capital intelectual: a nova vantagem competitiva das empresas. $5^{\text {a }}$ Edição. Rio de Janeiro: Campus.

VILHENA, João Baptista. (2004) - Responsabilidade Social: Vale a pena investir? Instituto MVC - Estratégia e Humanismo. Disponível em: http://www.institutomvc.com.br/costacurta/artjbv14_responsabilidade_social.htm. Acessado em 11/05/2004. 


\section{ANEXO 1 - Mapa estratégico proposto para a empresa pesquisada}



Buscar a satisfação dos clientes

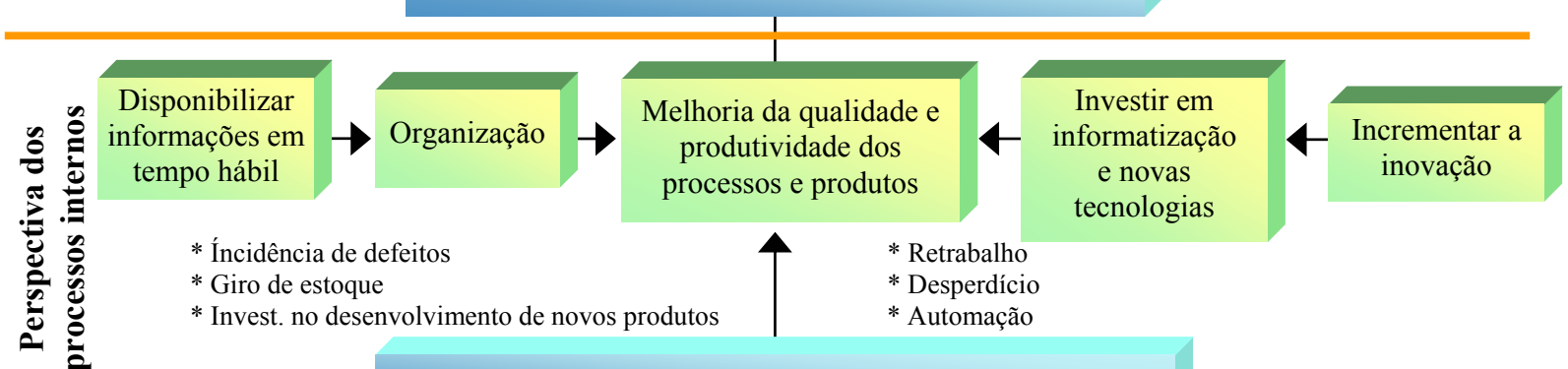

Competividade, informação, inovação e tecnologia

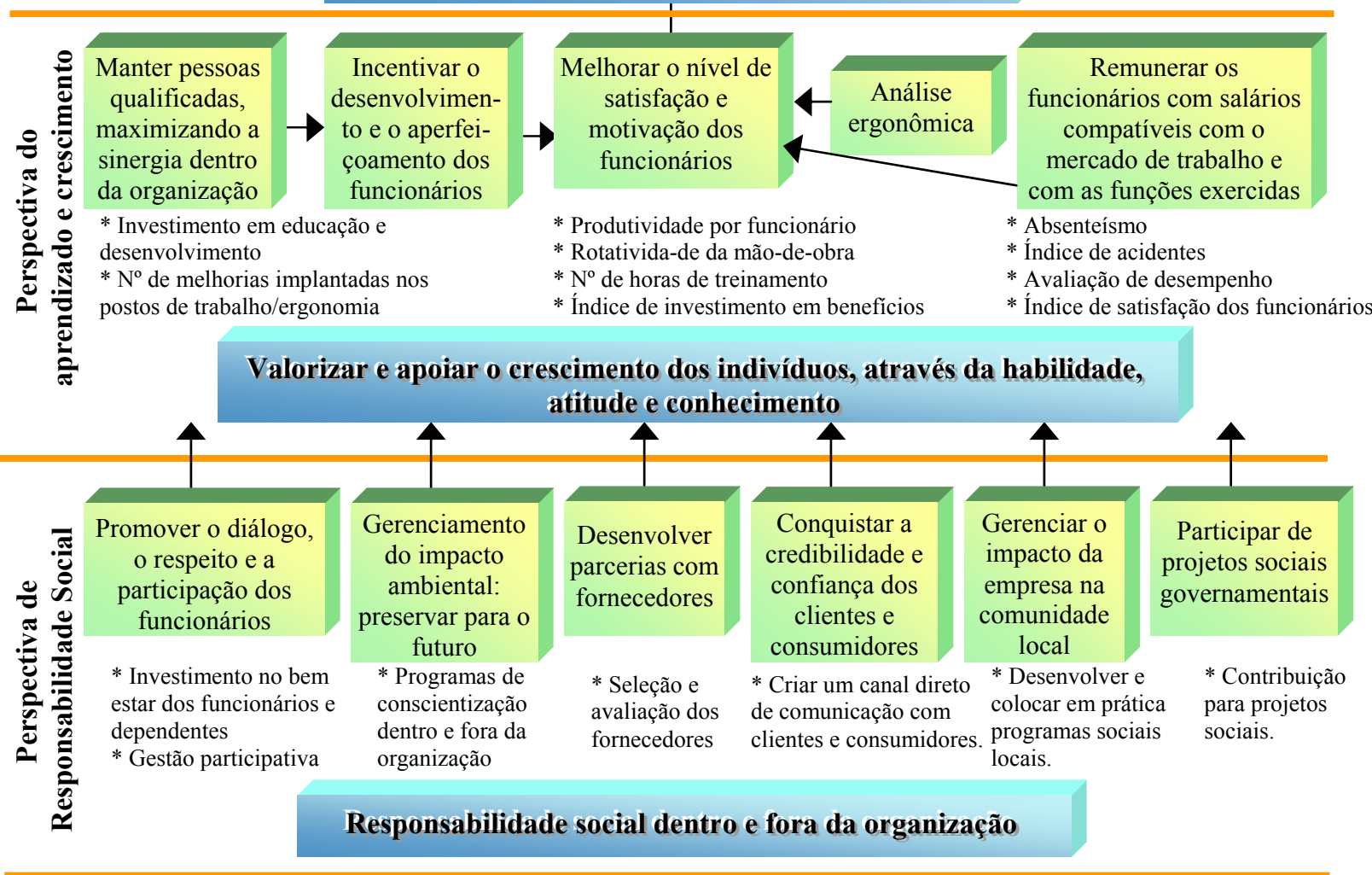

Fonte: (Adaptado de Kaplan e Norton, 2000) 